\section{(6) OPEN ACCESS}

\title{
Ethical and economic considerations of rare diseases in ethnic minorities: the case of mucopolysaccharidosis VI in Colombia
}

\author{
Diego Rosselli, ${ }^{1}$ Juan-David Rueda, ${ }^{1}$ Martha Solano ${ }^{2}$
}

${ }^{1}$ Clinical Epidemiology and Biostatistics, Pontificia Universidad Javeriana, Bogota, Colombia

${ }^{2}$ Department of Neuropediatrics, Fundacion Cardioinfantil, Bogota, Colombia

\section{Correspondence to}

Dr Diego Rosselli, Clinical Epidemiology and Biostatistics, Pontificia Universidad Javeriana, Carrera 7 No 40-62, Bogota 110311, Colombia; diego.rosselli@gmail.com

Received 25 August 2011 Revised 8 February 2012 Accepted 5 April 2012 Published Online First 1 May 2012

\begin{abstract}
Mucopolysaccharidosis $\mathrm{VI}$ is an autosomal recessive lysosomal storage disorder associated with severe disability and premature death. The presence of a mucopolysaccharidosis-like disease in indigenous ethnic groups in Colombia can be inferred from archaeological findings. There are several indigenous patients with mucopolysaccharidosis VI currently receiving enzyme replacement therapy. We discuss the ethical and economic considerations, regarding both direct and indirect costs, of a high-cost orphan disease in a marginalised minority population in a developing country.
\end{abstract}

Rare diseases warrant different ethical and economic considerations, particularly when present in indigenous populations or other minorities. Barriers to access, for both diagnosis and treatment, are exacerbated by geographical and cultural marginalisation, as well as by the institutional distrust that results from generations of neglect. In addition, isolation often leads to consanguinity, a breeding ground for recessive disorders. ${ }^{1}$ This paper describes some of the special considerations for an indigenous ethnic group affected by an autosomal recessive lysosomal storage disorder.

Mucopolysaccharidosis VI (MPS VI)-or Maroteaux-Lamy syndrome-is due to a lack of arylsulfatase $\mathrm{B}$, resulting in incomplete degradation and cellular accumulation of glycosaminoglycans, which leads to cell injury, severe disability and premature death. Estimated illness prevalence ranges from 1 in 43261 births in Turkish immigrants living in Germany ${ }^{2}$ to 1 in 1505160 births in Sweden. ${ }^{3}$ In Colombia, we know of 27 cases, 10 of which are in indigenous groups. This works out at an estimated prevalence of about 1 in 1700000 of the general population, or 1 in 140000 of the total population of indigenous people in Colombia. From any of these perspectives, MPS VI fits the definition of a 'very rare disease' (prevalence $<1$ per 50000 population). ${ }^{4}$

Treatment for MPS VI with galsufase (Naglazyme) was introduced in 2005 in the USA, and a year later in Europe, and has been approved by the FDA and EMA, the American and European agencies, respectively. 5 This enzyme replacement therapy (ERT) is administered through weekly intravenous infusion. Ideally, treatment should be initiated early, ${ }^{6}$ since tissue injury can be delayed but, at most, only partially reversed. Clinical trials have shown improvement in walking capacity, ${ }^{7}$ pulmonary function, ${ }^{8}$ and growth and pubertal development. ${ }^{9}$ In Europe, the cost per year per patient has been estimated to range between $€ 150000$ and $€ 450000$. $^{10}$

Evidence of the presence of an MPS-like disease dates back to prehistoric times in southwestern Colombia. Several clay figurines from the Tumaco culture (300 BC to $500 \mathrm{AD}$ ) depict patients with craniofacial and spinal malformation, interpreted by experts as cases of MPS. ${ }^{11-13}$ The Totoró is one of 82 indigenous groups that survive in Colombia; they live in the southwestern Andean highlands, and their population is estimated to be $4130 .^{14}$ Several cases of MPS VI have been confirmed in this and other indigenous groups in Colombia.

These patients normally have a late diagnosis and encounter various barriers to access to therapy, which are common findings in rare diseases. An ethical dilemma, often seen when treating indigenous groups, is the relationship with traditional healers, who are sometimes overtly opposed to orthodox medical interventions. This position adds to generalised distrust in Western medicine. In the case of the Totoró, we were not able to obtain informed consent to publish the case of a family with three affected siblings, with their difficulties for authorisation to receive ERT, and the consequent direct, indirect and intangible costs associated with their condition, despite the good response they have shown to the therapy.

A serious concern when treating these patients is the cost of therapy. In the treatment of very rare diseases, the cost of drugs is inversely proportional to the prevalence of the disease. ${ }^{15}$ There are two main reasons for this: first, the small number of patients who will use a drug (the actual 'market' for the drug) means that each individual patient will necessarily have to be charged a high fee; second, it is difficult to find enough patients for clinical trials. For example, the phase III trial that led to approval of galsufase for ERT required recruitment in 25 centres from 11 countries for a final sample of 39 patients. ${ }^{7}$ Patient scarcity has several consequences: it not only increases the time and number of sites involved in a trial, it also leads to lower statistical power and less chance of proving differences between treatment alternatives. Once the benefit was proven in the above trial, for ethical reasons all patients in the trial received ERT, losing the advantages of a placebo control group.

The first tendency of most medical decision makers is to reject the possibility of ERT, on the basis of its high opportunity cost (alternative uses for these resources). On the other hand, those who support paying the costs of treating rare disease 
advocate the 'rule of rescue', originally proposed by Jonsen in 1986 (cited in Cookson et $a l^{16}$ ), which refers to the social imperative to rescue identifiable individuals who face avoidable death (or severe disability). These interventions would not fit the conventional definitions, or fixed thresholds, of 'cost-effectiveness'. The social value attached to rescuing shipwrecked sailors or trapped miners is an example of this rule. The experience with the 33 Chilean miners confined hundreds of feet underground is a recent example. Nobody questioned the 20 million dollars or so invested in their rescue. ${ }^{17}$ The same budget would be needed to treat a similar number of patients with MPS VI for 3 years in Colombia. Life-threatening decisions made by people who have not seen the patients and their families should, in our opinion, always be questioned.

According to the Australian Pharmaceutical Benefits Advisory Committee, there are three requirements for the application of the rule of rescue: (1) there is no existing alternative treatment; (2) the medical condition should be severe, progressive and decrease life expectancy; and (3) the number of patients affected should be 'very small'. ${ }^{16}$ Another argument in favour of treating rare diseases is the relatively low impact of these costs on the national healthcare budget.

Cost-effectiveness studies do not usually include out-ofpocket expenses, or indirect and intangible costs, which in our particular cases are significant. Transportation to specialised centres for ERT, for both the patient and a care giver, can represent a high burden for a poor family. Academic performance and employment possibilities have been hindered for the whole family of our patients, including unaffected siblings. Untreated patients encounter even higher out-of-pocket indirect and intangible costs, such as higher costs associated with complications, more frequent healthcare encounters, and more care giver dedication. The heaviest burden in these diseases usually falls on the mother, whose quality of life is most seriously affected, and in ways that are difficult to quantify. When denying ERT, most decision makers are not considering the direct, indirect and intangible benefits obtained by the care givers.

Access to treatment has been a serious problem for indigenous patients with MPS VI who have to travel $2-4 \mathrm{~h}$ to the nearest infusion centre. Our patients have received less than half of the infusion sessions prescribed, mostly because each intravenous infusion requires the approval of the local health authority, a bureaucrat in the provincial capital who perhaps sees this as a distant (and expensive) problem.

In the long run, the burden of MPS VI and other inherited disorders could be reduced with genetic counselling and screening in high-risk populations. Currently, the Colombian Ministry of Health is considering the introduction of tandem mass spectrometry for neonatal screening of metabolic disorders. A promising example of the benefits of screening has been set with Tay-Sachs syndrome, an inherited lysosomal sphingolipid storage disorder common in Ashkenazi Jewish populations. Genetic screening has resulted in a $90 \%$ reduction in its incidence in selected groups. ${ }^{18}$ Couples with early detection in pregnancy must then make the difficult decision between abortion and continuing with pregnancy. Other alternatives include adoption, preimplantation genetic diagnosis, and artificial insemination.
In conclusion, orphan diseases, particularly in minorities, should be addressed cautiously. Application of normal thresholds for cost-effectiveness do not apply in these circumstances, where distributive justice should be a main concern. This has led to special regulations and financing schemes for rare diseases. In addition, indirect and intangible costs and benefits should always be taken into account before an expensive treatment is denied.

Acknowledgements Biomarin Colombia supported the research team, covering travel expenses to visit the indigenous community.

Contributors DR had the original idea for this paper. JDR performed the literature search and wrote the first draft. MS knew the patients and is the local expert in MPS VI. All the authors contributed to the discussion and approved the final version.

Funding This study was supported by Biomarin Colombia.

\section{Competing interests None.}

Provenance and peer review Not commissioned; externally peer reviewed.

\section{REFERENCES}

1. Trachtenberg EA, Keyeux G, Bernal JE, et al. Results of Expedicion Humana. I. Analysis of HLA class II (DRB1-DQA1-DPB1) alleles and DR-D0 haplotypes in nine Amerindian populations from Colombia. Tissue Antigens 1996:48:174-81.

2. Baehner F, Schmiedeskamp C, Krummenauer F, et al. Cumulative incidence rates of the mucopolysaccharidoses in Germany. J Inherit Metab Dis 2005;28:1011-17.

3. Malm G, Lund AM, Månsson JE, et al. Mucopolysaccharidoses in the Scandinavian countries: incidence and prevalence. Acta Paediatr 2008;97:1577-81.

4. Miles KA, Packer $C$, Stevens A. Quantifying emerging drugs for very rare conditions. OJM 2007;100:291-5.

5. Giugliani R, Harmatz P, Wraith JE. Management guidelines for mucopolysaccharidosis VI. Pediatrics 2007:120:405-18.

6. Auclair D, Hopwood JJ, Brooks DA, et al. Replacement therapy in mucopolysaccharidosis type $\mathrm{Vl}$ : advantages of early onset of therapy. $\mathrm{Mol}$ Genet Metab 2003;78:163-74.

7. Harmatz P, Giugliani R, Schwartz I, et al. Enzyme replacement therapy for mucopolysaccharidosis VI: a phase 3, randomized, double-blind, placebo-controlled multinational study of recombinant human $\mathrm{N}$-acetylgalactosamine 4-sulfatase (recombinant human arylsulfatase B or rhASB) and follow-on, open-label extension study. J Pediatr 2006;148:533-9.

8. Harmatz P. Enzyme replacement therapy for mucopolysaccharidosis VI: evaluation of long-term pulmonary function in patients treated with recombinant human $\mathrm{N}$-acetylgalactosamine 4-sulfatase. J Inherit Metab Dis 2010;33:51-60.

9. Decker C, Giugliani R, Schwartz IV, et al. Enzyme replacement therapy for mucopolysaccharidosis Vl: growth and pubertal development in patients treated with recombinant human $\mathrm{N}$-acetylgalactosamine 4-sulfatase. J Pediatr Rehabil Med 2010;3:89-100.

10. Schlander $\mathbf{M}$, Beck M. Expensive drugs for rare disorders: to treat or not to treat? The case of enzyme replacement therapy for mucopolysaccharidosis VI. Curr Med Res Opin 2009;25:1285-93.

11. Bernal J, Briceño I, Duncan R. El arte del chamanismo, la salud y la vida, Tumaco-La Tolita. Bogotá: Instituto Colombiano de Cultura Hispánica, 1993.

12. Rodríguez CA, Pachajoa H. Salud y enfermedad en el arte prehispánico de la cultura Tumaco-La Tolita. Cali: Editorial Universidad del Valle, 2010.

13. Bernal JE, Briceno I. Genetic and other diseases in the pottery of Tumaco-la Tolita culture in Colombia-Ecuador. Clin Genet 2006;70:188-91.

14. Sánchez E, Arango R. Los pueblos indígenas de Colombia en el umbral del nuevo milenio. Bogota: Departamento Nacional de Planeación, 2004. http://www.dnp.gov. co (accessed 4 Mar 2011).

15. Tambuyzer E. Rare diseases, orphan drugs and their regulation: questions and misconceptions. Nat Rev Drug Discov 2010;9:921-9.

16. Cookson R, McCabe C, Tsuchiya A. Public healthcare resource allocation and the Rule of Rescue. J Med Ethics 2008;34:540-4.

17. Lane E. Chile mine rescue to cost $\$ 20 \mathrm{~m}$. BBC News. 14 October 2010. http://www.bbc.co.uk/news/business-11541634 (accessed 31 May 2011).

18. Kaback M, Lim-Steele J, Dabholkar D, et al. Tay-Sachs disease-carrier screening, prenatal diagnosis, and the molecular era: an international perspective, 1970 to 1993. JAMA 1993:270:2307-15 